\title{
Congenital nystagmus among the Red-skins of the Highlands of Papua New Guinea
}

\author{
R. W. HORNABROOK, W. I. MCDONALD, AND R. L. CARROLL \\ From the Institute of Medical Research of Papua New Guinea
}

SUMMARY Sixty-four people with pigmentary anomalies of the skin were examined in the Eastern Highlands of New Guinea. Thirty-one had a bronze-red skin colour which appears to be unique to New Guinea. Eighteen of the Red-skins had congenital nystagmus which was not associated with impairment of visual acuity. The fundi were normal. The pigmentary anomaly is recessively inherited, and the gene responsible for the nystagmus appears to be associated with those controlling skin colour. The condition appears to be a unique form of albinism and confers no disadvantage on those who have it.

It has long been known that among the indigenous people of New Guinea live a small number of individuals whose skin pigmentation is strikingly different from that of their fellows. D'Albertis ${ }^{1}$ described his observations during the course of an epic navigation of the Fly river deep into the interior in 1871-3 as follows: 'A great surprise was however in store for me. Presently, a man walked in as the others had done, armed and adorned with flowers and necklaces, like them but accompanied by a son of about 25 and a daughter of about 20, both of them were albinos. Their hair is whitey-brown, their eyes blue and their skin white, like that of Europeans'.

Mikloucho-Maclay, ${ }^{2}$ who explored the coast east of the Eastern Highlands near Madang from 1871 to $1883,{ }^{3}$ noted 'albinism- $\frac{1}{2}$ albinism not rare'.

The earliest observation of light-skinned people in the Eastern Highlands themselves appears to have been made by one of the first explorers, Dr H. F. W. Bergmann, a missionary who entered the region in 1929 (Sentinella, personal communication). In his as yet unpublished book he says: 'Nearly everywhere in New Guinea, almost in every tribe, there are some so-called albinos. Amongst the Kamanuku and the surrounding tribes there are also a few of them but not very many. The skin of these people is quite light coloured, nearly a reddish-white. Also the eyes have less pigment and are sensitive to light. The colour of

Correspondence to Professor W. I. McDonald, Institute of Neurology, National Hospital, Queen Square, London WC1N 3BG. them varies, some are very light, others are only a bit light. The hair is mostly red or reddish-white. The skin is mostly full of freckles . . . . Each tribe knows that such people are there and find it quite normal. They call them kuruo, which we must translate with white or yellow-white or yellow-red'.

This description obviously includes light-skinned individuals other than albinos. A specific distinction is made by Vogel, ${ }^{4}$ who went to New Guinea in 1950 , and on his way to investigate the Jimmi River pygmies he noted that at Meguagi there were 'several people the colour of whose skin was quite different to that of the majority. Their complexion was very light, reminiscent of ours when we are slightly sunburnt. On the whole the appearance of these people is the same as all the others, except that their curly hair is more brown than black, in certain cases bordering on fair. I had also observed such oddities in the Wahgi valley. They are not albinos...'.

It is interesting that he did not see any lightskinned individuals among the pygmies.

It is now agreed that there are four easily distinguished types of skin pigmentation among the New Guineans: black (typically Melanesian), red, pale brown, and white (the true albino). ${ }^{56}$ Red-skins have recently attracted particular attention from geneticists and biochemists because they appear to be unique to New Guinea. In the Eastern Highlands they account for approximately $2 \%$ of the population, and the determining gene behaves as an autosomal recessive. ${ }^{6}$ The precise origin of the skin colouration has not been established. It is not a result of dietary deficiency, since the nutritional state of the population has been reported on, ${ }^{78}$ 
and there is no evidence that that of the Red-skins is different from that of the black Melanesians. There is some evidence that the melanocytes of the Red-skin are morphologically distinctive and that the red colouration may be due to the presence in the epidermis of a phaeomelanin. ${ }^{9}$

These investigations into the nature and inheritance of the pigmentary anomaly of the Red-skin have not been accompanied by a detailed clinical description. While we and others have noted that nystagmus occurs in an appreciable proportion of the Red-skin group, ${ }^{5}$ the data on visual function are fragmentary. We report here the results of a clinical study carried out in the Goroka district of the Eastern Highlands.

\section{Subjects and methods}

Hamlets and villages were visited in the Asaro and Bena Bena valleys and in the Lufa subdistrict and inquiries made as to whether there were any individuals there with unusual pigmentation. Examination was carried out either in the Institute of Medical Research in Goroka or in a clinic temporarily set up in Lufa. A family with a sibship of 8, of whom 4 were albinos, was examined in Madang.

Skin, hair, and iris colour were recorded. Visual acuity was ascertained with a Snellen chart, and colour vision was tested with the American Optical Society's pseudo-isochromatic plates (Hardy-Rand-Rittler). The fundi were examined by direct ophthalmoscopy and photographed in selected cases. Initially all subjects were examined with dilated pupils, but since this caused distress because of the bright ambient light most later subjects were examined with pupils undilated. The eye movements and pupils were examined and a general neurological assessment was carried out.

\section{Results}

\section{SKIN COLOUR}

Previous investigations have established an incidence of $1.5-2 \%$ of Red-skins in the Goroka district. ${ }^{56}$ We examined 64 individuals (some of whom had been included in Harvey's survey), who were readily classified into 3 groups according to the appearance of the skin: Red-skins. Thirty-one individuals showed the characteristic bronze-red skin colour (Fig. 1). Pale-skins. Twenty-six individuals had skin of a uniform café-au-lait colour. Freckled Pale-skins. Seven individuals had very pale brown skins with darker freckles and were categorised separately. Freckling was not a feature of the Red-skins.
The hair colour ranged from very fair to black, and as noted by both Walsh ${ }^{6}$ and Harvey, ${ }^{5}$ there was a poor correlation between hair colour and the intensity of the reddish-brown skin pigmentation. It is nevertheless the case that natural fair hair is seen only among the 3 groups of subjects described here, together with the rare true albinos (Fig. 2), and not among the black Melanesians. However, ritual colouration of the hair with clay and bleaching with lime are common.

\section{IRIS COLOUR}

The normal iris colour of the black Melanesian is a deep uniform brown (Fig. 3). Somewhat more than one-third of the individuals with pigmentary anomalies had a variable amount of grey colouration in the iris. This finding was most marked and most frequent in the Freckled Pale-skins (6/7). Only one of these 7 had a uniform brown iris, 1 had a speckled grey-brown iris, and in the remaining 5 the iris was a uniform grey. Twelve of the 25 Pale-skins had a more or less grey iris: 5 were plain grey and 7 contained a mixture of brown pigment (Fig. 4). In contrast only 6 of 29 Red-skins showed any grey in the iris, and in all of these patches of brown pigment were obvious. Iris colour in the remainder was indistinguishable from normal (cf. Figs. 3 and 5).

\section{TRANSLUCENCY}

Albinism may be suspected when there is an increase in translucency of the iris in response to the application of a bright focal light source to the sclera. In our investigation we were restricted to the use of a bright pocket torch and examination in a darkened room. In the normal dark Melanesian in these conditions a faint glow was visible obliquely through the pupil, but there was no translucency of the iris. In the 25 Red-skins examined 6 showed iris translucency, 4 of these having grey iris colouration and 2 having brown irides. Nine of the 17 Pale-skins and 6 of the 7 Freckled Pale-skins showed an increase in translucency of the iris, which in each case showed grey colouration. Classical oculocutaneous albinos seen in Madang showed brilliant translucency of the iris, much more striking than any seen in the Highland groups (Fig. 6). The translucency observed in the Red-skins and Paleskins was nevertheless abnormal and indicates hypopigmentation of the iris, similar to that seen in some forms of tyrosinase-positive oculocutaneous albinism.

\section{NYSTAGMUS}

The most frequent and striking abnormality was congenital nystagmus. In most patients it was present in the primary position, where it was usually 


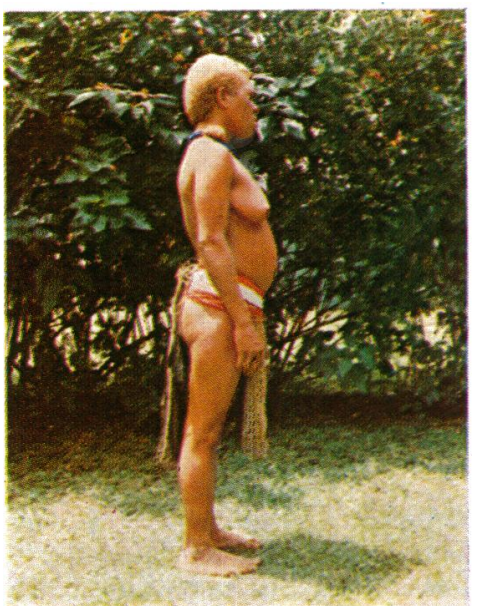

Fig. 1 A Red-skin

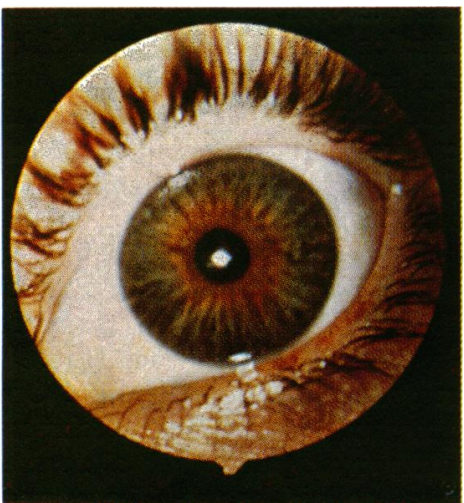

Fig. 4 Iris of a Pale-skin

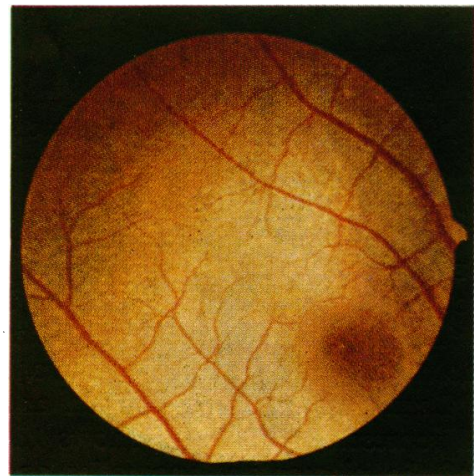

Fig. 7 Macular region of a blackpigmented Melanesian

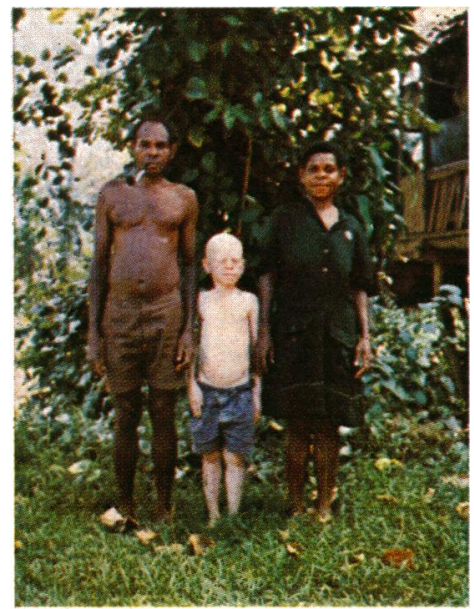

Fig. 2 An albino child with his normally pigmented Melanesian parents

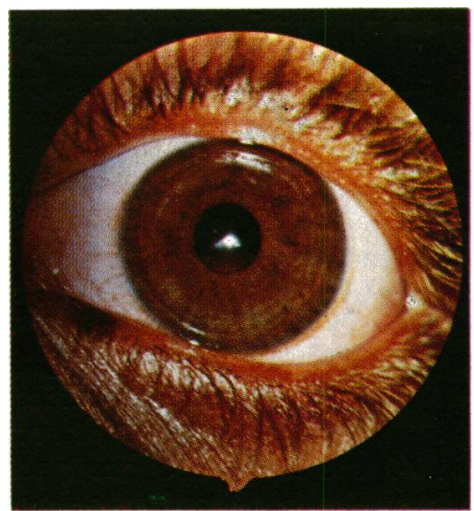

Fig. 5 Iris of a Red-skin

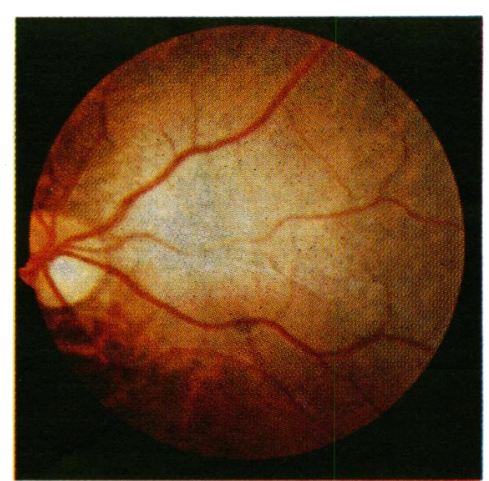

Fig. 8 Fundus of a Red-skin showing a tigroid pattern

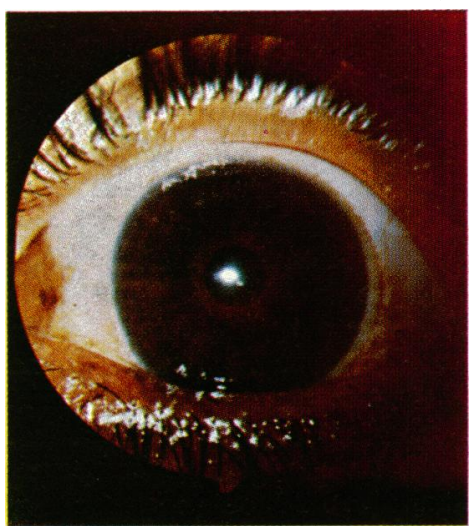

Fig. 3 Iris of a normally pigmented black Melanesian

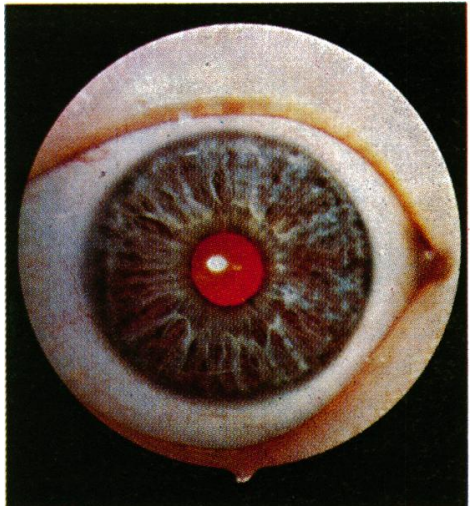

Fig. 6 Iris of an albino showing striking translucency

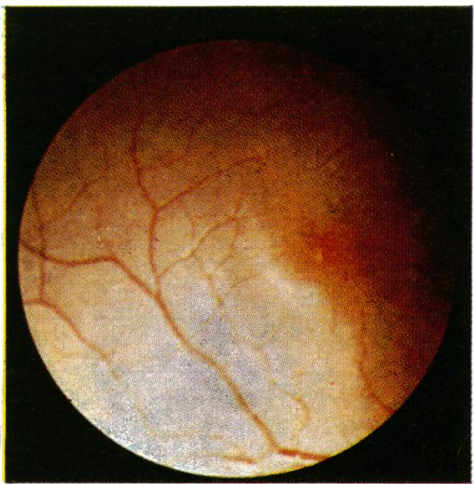

Fig. 9 Macular region of $a$ Pale-skin 
pendular. Conjugate lateral gaze increased the coarseness of the nystagmus, which usually then took on a jerky component with the quick phase in the direction of gaze. On vertical upward and downward gaze the nystagmus remained in the horizontal plane. Optokinetic nystagmus was examined by means of a tape with alternating dark and light stripes. Satisfactory observations were made in 22 patients with nystagmus. We observed a normal optokinetic response in both horizontal and vertical planes in 3 individuals only. The horizontal response was absent in 12 and the vertical was absent in 5 . The most common abnormality was a decrease in amplitude of the optokinetic response, more often in the horizontal than in the vertical plane, sometimes more marked in one direction of gaze than others. In individuals with nystagmus in the primary position vertical movement of the tape usually induced optokinetic nystagmus in an oblique plane. The null point for the nystagmus was usually eccentric, resulting in the adoption of a compensatory head posture. Titubation was present in a few patients.

The incidence of nystagmus in the patient groups is shown in Table 1. No example was seen in the control group. Overall, nystagmus occurred in 58\% of those with pigmentary anomalies of the skin. Comparison of the incidences between groups showed a marginally significant difference only between the Pale-skins and the Freckled Pale-skins $\left(\chi^{2}=4.93, P=0.025\right)$, but the numbers are too small to draw firm conclusions.

\section{VISUAL ACUITY}

The visual acuity was measured in 49 subjects, including 33 of the 34 with nystagmus. Ten had abnormal acuities, 1 without nystagmus having a retinal detachment. In the remaining 9, all with nystagmus, the acuity deficit was unilateral in 2 (1 of whom had a concomitant strabismus on the affected side). Of the remaining 7,5 had $6 / 9$ vision in one (1) or both (4) eyes. Except for the subject with strabismus, the mechanism of impairment was not established, although 1 patient had opacities in the media. The optic discs were normal in all. The retinae and maculae were examined through

Table 1 Incidence of nystagmus

\begin{tabular}{lll}
\hline Skin colour & No. examined & No. with nystagmus \\
\hline Red & 31 & 18 \\
Pale & 26 & 10 \\
Freckled pale & 7 & 6 \\
Total & 64 & 34 \\
\hline
\end{tabular}

dilated pupils in 3 of the subjects in the group with nystagmus. All were normal (see below).

Since there was no impairment of acuity in 24 of the 33 subjects with nystagmus examined and in 7 of the remainder the impairment was unilateral and/or mild (visual acuity $6 / 9$ or better) it is obvious that the occurrence of nystagmus is independent of acuity impairment. The overall results show that Red-skins, unlike classical oculocutaneous albinos, do not show a constant association between the pigmentary anomaly of the skin and impairment of acuity.

\section{FUNDI}

The fundi were examined in 45 subjects, 18 with the pupils dilated. Thirty-three of the 34 patients with nystagmus were examined, 10 through dilated pupils. A satisfactory assessment of the peripapillary retina could be made in 19 of the undilated subjects with nystagmus. In the dilated subjects a thorough examination of disc, macula, and retina was possible. In all subjects the optic discs were normal. The retinal pigmentation in the 3 abnormal skincolour groups (with and without nystagmus) was indistinguishable from that of black Melanesians, of whom 30 were examined in the present study and many hundreds of whom have been examined by R. W. H. in the course of 10 years of neurological work in the New Guinea Highlands. The retina itself tended to be somewhat darker than that of Europeans (Fig. 7) and frequently had a tigroid pattern (Fig. 8). The maculae were normal (Fig. 9). Abnormalities were found in 2 subjects only. One patient without nystagmus had a retinal detachment and one patient with nystagmus (but a normal acuity) showed retinal colloid bodies. The normal appearance of the retinae in the Red-skins, Paleskins and Freckled Pale-skins contrasted sharply with that of the 4 oculocutaneous albinos seen in Madang, all of whom had typical albinoid fundi.

\section{COLOUR VISION}

Colour vision was tested in all those old enough to co-operate (50). No abnormality was detected, except in the single eye with retinal detachment, in which the acuity was less than $6 / 60$.

AGE, SEX, AND ETHNIC GROUP

Nystagmus was seen in subjects of all ages from 2 years to over 50 (the age of older New Guineans is not usually known accurately). The 5 language groups (Gahuku, Bena Bena, Asaro, Yagaria and Chimbu) were all represented. Table 2 shows the sex distribution of the pigmentary anomalies and nystagmus. There was no significant difference in the incidence of nystagmus between males and 
Table 2 Relationship between sex* $\dagger$ and incidence of nystagmus

\begin{tabular}{|c|c|c|c|c|c|}
\hline & Males & $\begin{array}{l}\text { No. with } \\
\text { nystagmus }\end{array}$ & Females & $\begin{array}{l}\text { No. with } \\
\text { nystagmus }\end{array}$ & $x^{2}$ \\
\hline Red-skins & 18 & 12 & 11 & 5 & $1.27 \mathrm{NS}$ \\
\hline Pale-skins & 14 & 7 & 10 & 3 & $0.96 \mathrm{NS}$ \\
\hline $\begin{array}{l}\text { Freckled } \\
\text { pale-skins }\end{array}$ & 3 & 3 & 4 & 3 & NSt \\
\hline Total & 35 & 22 & 25 & 11 & $2 \cdot 10 \mathrm{NS}$ \\
\hline
\end{tabular}

*There was in addition one hermaphrodite Red-skin with nystagmus †The sex was not noted in 3 further subjects. ‡Fisher's exact test, $\mathbf{P}=\mathbf{0} \cdot 57$.

Table 3 Relationship between sex and Red-skin anomaly

\begin{tabular}{llll}
\hline & Red-skins & Others & Total \\
\hline Male & 17 & 18 & 35 \\
Female & 14 & 11 & 25 \\
Total & 31 & 29 & 60 \\
\hline
\end{tabular}

females in any group. The difference in frequency of males and females in the Red-skin group was not significant either (Table $3: x^{2}=0.323 ; \mathrm{P}=0.58$ ).

\section{Discussion}

Congenital nystagmus occurs in association with anomalies of skin and iris pigmentation in the Eastern Highlands of New Guinea. Previous surveys have reported an incidence of $1.5-2 \%$ of Redskins, ${ }^{56}$ and in 2 villages near Maprik, with a population of 553 , the incidence reaches $3.8 \%$. The present investigation has shown that approximately two-thirds of such individuals have nystagmus-a remarkably high incidence in comparison with European populations.

The Red-skin colour is inherited recessively. ${ }^{56}$ The mutation rate must be very low, since although Red-skins are widespread in the Highlands and we have seen them in the Gulf of Papua and in the Sepik (but not on Kar Kar Island), they have not been identified outside Papua New Guinea. An incidence of $2 \%$ is high for a recessive condition and indicates that neither the pigmentary anomaly nor the nystagmus confers a disadvantage for survival on the affected individuals. Such a situation could result from a selective advantage of Red-skins in infancy in areas of high infant mortality. This explanation would account for the remarkably high gene frequency. ${ }^{6}$ An additional factor contributing to the high frequency of the Red-skin gene may be a social one: Red-skins are much sought after as wives.

The circumstances of the albino are quite differ- ent. The extreme photophobia and the poor acuity dictate a pattern of life different from that of other New Guineans: the albino spends the day indoors or in the shade and takes little part in tending the gardens and hunting. Despite these precautions, the incidence of basal cell carcinoma of the skin is high in albinos. Neither in the present investigation nor in that of Walsh ${ }^{6}$ has a single example of skin cancer been seen among the Red-skins. Although we did observe some photophobia, it did not interfere with the normal activities of the Red-skin.

It is clear from our investigations that the gene responsible for the inheritance of nystagmus is closely associated with genes controlling eye and skin colour. More detailed family studies are required to establish whether the same or separate genes are involved.

Finally, the question arises whether the Red-skins should be regarded as having a form of albinism. Witkop ${ }^{10}$ adopts a broad definition of albinism as 'a hereditary defect in the metabolism of melanin, resulting in a decrease or absence of this pigment in skin, mucosa, hair or eyes'. Although histological observations suggest that there may be some reduction in the overall amount of melanin in the skin of the pale brown individual and a small reduction in the Red-skin, ${ }^{9}$ quantitative data are lacking and the evidence is not conclusive. The ocular abnormalities of the Red-skin differ in some respects from those of the albino. Whereas in albinos nystagmus is invariable and is always associated with impaired acuity, nystagmus is absent in one-third of Redskins and when present is unrelated to acuity. Iris translucency is striking in the oculocutaneous albino but is infrequent and of relatively minor degree in the Red-skin. Finally the fundus of the Red-skin is ophthalmoscopically normal. These differences are, however, a matter of degree, and we conclude that the Red-skin anomaly falls within Witkop's definition of albinism and represents a unique form of it.

We are grateful to E. H. O. King and A. McGregor for assistance in the field, to Dr M. Barraitser, Dr D. A. S. Compston, Mr Barrie Jay, and Dr S. Sergeantson for advice, and to Professor Barrie Jones for the loan of equipment. We are indebted to $\mathrm{Mr} \mathrm{C}$. L. Sentinella, editor of the Mikloucho-Maclay Diaries, for his generous help in identifying early references to albinos and Red-skins in Papua, New Guinea.

\section{References}

${ }^{1}$ D'Albertis LM. New Guinea: What I did and what I saw, 2nd ed. London: Sampson Low, Marston, Searle and Rivington, 1881 : 1 : 108.

${ }^{2}$ Mikloucho-Maclay NN. From notes for a lecture delivered in St. Petersburg, November 1886. Sobranie Sochinenii. Moscow Academy of Sciences, 1951; 3: 427 (cited by C. L. Sentinella, personal communication). 
'Sentinella CL. Mikloucho-Maclay: New Guinea Diaries 1871-1883, 2nd ed. Madang, Papua, New Guinea: Kristen Press, 1977.

${ }^{4}$ Vogel AA. Papuans and Pygmies. London: Barber, 1953.

${ }^{5}$ Harvey RG. The 'Red-skins' of Lufa sub-district. Further observations on the distinctive skin pigmentation of some New Guinea indigenes. Human Biology in Oceania 1971; 1: 103-13.

'Walsh RJ. A distinctive pigment of the skin in New Guinea indigenes. Ann Hum Genet 1971; 34: 379-85.

${ }^{7}$ Hornabrook RW, Crane GG, Stanhope JM. Karkar and Lufa: An epidemiological and health background to the human adaptability studies of the International Biological Programme. Philos Trans $R$ Soc Lon (Biol) 1974; 268: 293-308.

${ }^{8}$ Norgan NG, Ferro-Luzzi A, Durnin JBGA. The energy and nutrient intake and the energy expenditure of 204 New Guinean adults. Philos Trans $R$ Soc Lond (Biol) 1974; 268: 309-48.

'Nixon PF. The 'Red-skinned' New Guinean: Distinctive melanocytes. Pigment Cell 1973; 1: 6-13.

${ }^{10}$ Witkop CJ. Albinism. In: Harris H, Hirschorn K, eds. Advances in Human Genetics, New York: Plenum Press, $1971 ; 2$. 